\title{
Inter-observer agreement on visual colour matches and the role of metamerism as a cause of disagreement
}

DOI:

10.1007/BF02699749

Document Version

Accepted author manuscript

Link to publication record in Manchester Research Explorer

\section{Citation for published version (APA):}

Oulton, D., \& Taylor, H. (2002). Inter-observer agreement on visual colour matches and the role of metamerism as a cause of disagreement. Surface Coatings International Part B: Coatings Transactions, 85(2), 105-109. https://doi.org/10.1007/BF02699749

\section{Published in:}

Surface Coatings International Part B: Coatings Transactions

\section{Citing this paper}

Please note that where the full-text provided on Manchester Research Explorer is the Author Accepted Manuscript or Proof version this may differ from the final Published version. If citing, it is advised that you check and use the publisher's definitive version.

\section{General rights}

Copyright and moral rights for the publications made accessible in the Research Explorer are retained by the authors and/or other copyright owners and it is a condition of accessing publications that users recognise and abide by the legal requirements associated with these rights.

\section{Takedown policy}

If you believe that this document breaches copyright please refer to the University of Manchester's Takedown Procedures [http://man.ac.uk/04Y6Bo] or contact uml.scholarlycommunications@manchester.ac.uk providing relevant details, so we can investigate your claim.

\section{OPEN ACCESS}




\title{
Inter-observer agreement on visual colour matches and the role of metamerism as a cause of disagreement
}

\section{P Oulton and H Taylor}

UMIST Dept of Textiles, PO Box 88, Sackville Street, Manchester M601QD, United Kingdom

\begin{abstract}
Summaries
Inter-obseruer agreement on yisual colour matches and the role of metamerism as a cause of disagreement

The phenonenon is investigated, of 'Observer Metamerism' (one iliuminant, ho differing observersi, as distinct from liluminant Metanerism (one observer and wo differing light sources). Difference in colour perception is ouariffied by the CIE Colour Matching Fundions or CHFS which map response with respect to wavelength. The size of potential misnatches is quantified using calculations which compare co-ordinates, derived from the CMFs of to individual observers, with co-ordinates derived from the Standard Observer Chfs as a constant reference. The individual CMFs used are those of 10 of the observers whose colour matching responses were used in the 1964 Supplementany Standard observer average. The colourincoristancy results found on change of observer, suggest a level of observer-metameric effects that is likely to affect visual matching judgements by a high proportion of individual observers. The data suggest that in practical situations, two individuals are likely to disagree on both the magnitude and direction of visibie colour difference in metameric matches, and individual obseryers may also dispute the presence or absence of a visibie metameric difference in many sample pair comparisons.
\end{abstract}

L'accord entre observateurs sur concordances de couleur visuelles el le role de metamerisme comme une cause de desaccord

On étudie le phénomène de "métamérisme de l'observateu" (une source lumineuse, deux obsenvateurs différents) par opposition à "métamérisme de la source lumineuse" (un observatier, delx sources Iumineuses différentes). Une différence en la perception de coulaur est déterminée quantitivement par les CIE Colour Matching Functions ou CMFs, qui tracent la réponse a "egard de la lonigueir d'onde. Le talux de fausses concordances de couleur est determiné quantitivementit en se seryant des calculs ain mettent en comparaison les coordonnées prowenant des CMFs de 10 observateurs individuels avec coordonnées provenant des CMFs du Standard Obseverer comme une référence constante. Les CMFs individieilles uitilisées sont celles des 10 des observateurs dont les réponses en termes de concordance de couleur ont été utilisées dans la 1964 Supplementary Standard observer moyenrié. Les résultats à l"égard de la inconstance de perception de couleur oue Pon trouve en changeant de l'observateur, suggèrent dans la pratique un niveait d'eftets observateur-métamériques qui ont probabiement un effet sur les iugements concerrant la concordance visielile de couletir par une proportion importante et la direction de différence visueile en couleur en les concordances de couleuir métaméricues et les observateurs individuels se peizent également disputer la présence et l'absence d'une visibie différence métanériqué en plusieures comparaisons jiumelles à titre d’échantillon.

\section{Zwischenbeobacheres Einuerstandnis uber visuelle Farbgleicheiten und die Rolle des Melameries als einer Uneingkeitsgrund}

Das Phäromen der "Beobachtermetamerie" (eine Lichtquelite, zwei verschiedene Beobachter) im Gegensaz der "Lichtquellemetamerien" (ein Beobachter und zwei verschiedene Lichtguelie) labt sich untersuchern. Ein Unterschied in Farbwahnehmung wird durch die CIE Colour Matching Functions oder CMFs, die Empfindichikeit bezuglich der Welleniänge vermesseri, quantifiziert. Das Ausmaß der potentiellen Fehianpassingen wird bei Benulzung, die sich Koordinaten yon die CMFs berichtet von to einzeinen Beobachter mit Koordinaten berichtet yon den Standard observer CMFs als konstante Bezugspunikt vergleichen, quantifiziert. Die angewander einzeinen CMFs sird diejenigen der 10 diesen Beobachter derer Farboleichneitsaniwoten werden in dem 1964 ar Supplementary Standard Obseryer Durchschnitt gebraucht. Die Farbungbeständigkeitsresultaten gefunden beim Wechsel des Beobachters legt eine Stufe beobachter-metarnerische Wirkungen, das wahrscheinilich ist sich auszzuwirken auf die Abriusterungsurteile eines höhen Verhältnisses der einzelner Beobachter nahe. Die Daten bringen, daß bei praktischen Situationen zwei Einzelpersonen werden wahrscheinlich nicht uberzueinstimmen in bezug auf die Größe und Pichting des visuelien Farbstands in metamerischen Abmusterungen und auch einzenne Beobechter könter! die Anweserheit oder Abwesenheit eines visuelier Metanerischabstands bei vielen Musternaaryergleichungen streiten.

UMST Dept of Textiles, P0 Box 88 , Sackville Street, Manchester, M60100, Urited Kingdom

Teil: +44 (0)161 2004127

Fax: $+44(0) 1612287040$

Email: davidoutongumistac uik

Copyrigh occA 2002 


\section{Introduction}

The CIE system is used to predict colour matches between measured samples with different reflectance curves. This is an example of 'conditional equivalence' or Metamerism. Illuminant-dependent visual equivalence, or llluminant Metamerism, is present for example, when a single observer experiences the same colour sensation from two samples with distinctly different reflectance curves, but experiences distinctly different sensations from the same sample pair when the illuminant is changed.

The phenomenon of 'Observer Metamerism' (one illuminant, two differing observers), is complemented by and distinct from Illuminant Metamerism (one observer and two differing light sources).

Observer Metamerism may be the underlying cause, when two coloured samples appear to be a perfect match to one observer, and appear to be a significant mismatch to a second observer under the same illuminant'. Commercial colour matching is often reported to produce disagreements of this type, and the disagreement can have serious consequences if one observer is the supplier and the other is the buyer. The characteristics and magnitude of metameric effects due to detailed variation in spectral response are analysed in the following account, and are found to give an additional potential for disagreement about conditional matches between pairs of surface colours.

Difference in colour perception between observers is caused by differences in the sensitivity of the colour receptors in the eye to different wavelengths of light. The sensitivities of the receptors are described by the CIE Colour Matching Functions (CMFs) which map response with respect to wavelength. These colour matching functions vary slightly from observer to observer, and the inter-observer differences lead to the phenomenon of Observer Metamerism.

The size of the change in sensation or 'colour inconstancy' caused by changing either the Illuminant or the observer depends on the spectral curves of the test colours. If the matching colour-pair members have a very different reflectance curve shape, and if the curves themselves have rapidly changing reflectance over short intervals of wavelength, then the size of the change in sensation is likely to be greater, even if the change is small in the spectral char- acteristics of the illuminant or observer curves.

The overall colour shift in the appearance of each member of a metameric pair is thus a spectral (ie n-dimensional combination of the illuminant and the observer-metameric contributions). A methodology is established in the following sections to characterise the observer-metameric component.

The method is established and validated:

a) by reference to a set of individual observers who are component members of the $196410^{\circ}$ Standard Observer:

b) by reference to a carefully chosen set of representative input reflectance curves, which sample colour space systematically.

lluminant-metameric effects will form the most obvious component of colour change, to which less obvious underlying observer-metameric effects may well be added. The two metameric effects may combine, easily exceeding visual tolerance. Conversely, there will be instances where they cancel out in an individual observer.

It is necessary to differentiate between colour inconstancy, in which two observers appear to 'see' different colours, and metameric effects. Even if one observer sees a different colour from another observer, the two observers may still agree on the illuminant-metameric effects that are present, and the observer-metameric colour inconstancy does not contribute to the overall metameric effect.

Individual observer effects are analysed separately and in combination with illuminant effects in the following account. Comparisons of colour inconstancy on change of observer are made for a test set of 32 reference colours defined by reflectance curves, and for a metameric pair of reflectance curves judged by the Standard Observer to be a visually close match under $\mathrm{D}_{65}$.

The potential for a mismatch to occur between metameric pairs is called the degree of metamerism in a given matching pair. A high degree of metamerism (ie a potential for generating a large colour difference when illuminant or observer is changed) occurs when the Spectral Power Distributions (SPDs) of the light entering the eye from each member of a sample pair is markedly different

During industrial colour reproduction the degree of metamerism between coloured sample-pairs is controlled, and reduced as far as possible by colouring agent selection. Ideally it would be reduced to zero by generating identical reflectance curves, giving a colour match under all conditions of illuminant and observer. In practice it is not possible to produce identical reflectance curves when the mixtures of colouring agent differ in the samples being matched, or the substrates are significantly different.

The relevant CIE publication on Observer metamerism' describes a 'Standard Deviant Observer', implying that observers are either deviant or 'normal'. The development of a new metamerism index for change in observer has recently been suggested.

\section{Practical procedures}

The size of potential mismatches that may cause disagreements in colour matching is quantified by the change in CIE co-ordinates produced on changing the observer. The calculations compare co-ordinates, derived from the CMFs of ten individual observers, with co-ordinates derived from the Standard Observer CMFs as a constant reference. The individual CMFs used are those of ten of the observers whose colour matching responses were mapped by Stiles and Burch and used in the 1964 Supplementary Standard Observer average. The Standard Observer is described in detail by Wyszecki and Stiles. ${ }^{2}$

The 1964 Standard Supplementary Observer specifies a colour in terms of its tristimulus values:

$$
\begin{aligned}
& X=\sum_{\lambda=\lambda a}^{\lambda b} E(\lambda) \cdot R(\lambda) \cdot \bar{x}(\lambda) \\
& Y=\sum_{\lambda=\lambda a}^{\lambda b} E(\lambda) \cdot R(\lambda) \cdot \bar{y}(\lambda) \\
& Z=\sum_{\lambda=\lambda}^{\lambda b} E(\lambda) \cdot R(\lambda) \cdot \bar{z}(\lambda)
\end{aligned}
$$

where $E(\lambda)$ is the energy distribution curve of the illuminant; $R(\hat{A})$ is the percentage reflectance of the surface at each wavelength; $\bar{x}, \bar{y}, \bar{z}$ are the tristimulus values for each wavelength interval; and $\lambda_{\mathrm{a}}$ to $\lambda_{\mathrm{b}}=400$ to $700 \mathrm{~nm}$.

It can be seen that equivalent tristimulus value totals can be obtained from dif-

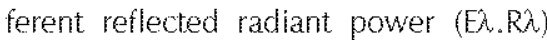
curves. For a constant pair of conditionally matching colours, previously equivalent tristimulus value totals may change if the observer, or illuminant change. This gives rise to lluminant Metamerism 
due to detailed SPD variation in the illuminant $(\mathrm{E})$, or equally to Observer Metamerism, due to detalled CMF variation in the observer (modelled by the $\bar{x}$, $\bar{y}, \bar{z})$.

In the investigation reported, CIE L*a*b* co-ordinates are used to quantify the sensation-difference $\Delta E^{*}$, between the tristimulus values derived for the two observers. Each individual observer is compared with the 1964 Standard Observer as a member of a metameric pair, by calculating tristimulus co-ordinates, for each of 32 reflectance curves of representative coloured samples. A sample by sample comparison is made with constant $D_{65}$ Standard Illuminant and a single reflectance curve. A total of 320 comparisons is reported.

A new index of Metamerism Index $M$, equal to the average $\Delta E *$ (CIE L* $a^{*} b *$, $\left.196410^{\circ} \mathrm{Obs}\right)$, for the given test set of 32 test colours is introduced in this paper.

The data used

1. $S(\lambda)$ Standard daylight illuminant $\mathrm{D}_{65}$ from ASTM designation: E308 95 'Standard Practice for Computing the Colours of Objects by using the CIE System'.

2. $\bar{x}, \bar{y}, \bar{z}$ The $1964 \bar{x}(\lambda), \bar{y}(\lambda), \bar{z}(\lambda)$ colour matching functions from E308 - 95, table 2, every $10 \mathrm{~nm}$ from 400 to $700 \mathrm{~nm}$, truncated as per section 7.3.2.2 of the publication. These provide the data for the reference observer in each metameric pair: the 1964 Supplementary Standard Observer. The data for the colour matching functions of the test observers are taken from the Stiles and Burch observer data used in the formulation of the 1964 standard observer. They are the first ten observers listed in Stiles and Wyszecki Colour Science: Concepts and Methods, Quantitative Data and Formulae' Second Edition. They have been changed to the CIE XYZ primaries.

3. $R(\hat{A})$ The reflectance curves are actual reflectance values measured on a Spectroflash SF 600 spectrophotometer at UMIST. The coloured samples are printed card reproductions from the Dulux Dimensions version of the NCS Colour System Colour Atlas.

The colours measured are taken from eight hue pages:

$R, Y, G, B$ and R50B, B50G, G50Y and Y50R, these latter four being $50: 50$ mixtures of their adjacent primary hues. Four samples were chosen from each page, covering the four possible combinations of high and low lightness with high and low chroma. They cover a substantial volume of colour space.

\section{Results}

The variation in the average degree of metamerism between different observers is substantial in terms of visible difference. Table 1 gives the mean $\Delta E *$ (CIEL*a*b* 1964 Standard Supple-
Table 1: Observer $\Delta \mathrm{E}^{*}$ for each colour group

\begin{tabular}{lcccccccccc} 
Colour & \multicolumn{10}{c}{ Observers } \\
\cline { 2 - 11 } & WSS1 & JMB2 & EMK3 & GEVL4 & MCB5 & DLT6 & EML7 & MHP8 & EA9 & RNW10 \\
\hline Blue & 0.84 & 1.58 & 2.64 & 4.33 & 1.65 & 0.97 & 0.79 & 1.89 & 1.36 & 2.98 \\
Red-Blue & 0.56 & 0.90 & 0.71 & 0.89 & 0.53 & 0.44 & 0.27 & 0.63 & 0.82 & 0.23 \\
Red & 1.38 & 0.98 & 1.81 & 1.10 & 0.72 & 0.44 & 0.55 & 0.38 & 1.75 & 1.93 \\
Red-Yellow & 0.92 & 1.11 & 1.42 & 1.86 & 0.41 & 0.38 & 0.55 & 0.81 & 1.20 & 2.19 \\
Yelilow & 1.23 & 1.57 & 1.41 & 3.06 & 1.26 & 0.92 & 0.94 & 1.59 & 1.41 & 2.51 \\
Yellow-Green & 1.03 & 1.23 & 0.60 & 2.02 & 1.00 & 0.66 & 0.54 & 1.17 & 1.09 & 1.05 \\
Green & 0.60 & 1.46 & 1.82 & 0.90 & 0.41 & 0.16 & 0.19 & 0.38 & 1.07 & 1.42 \\
Green-Blue & 0.99 & 1.09 & 1.99 & 1.91 & 0.71 & 0.34 & 0.38 & 0.64 & 0.85 & 1.91 \\
\hline
\end{tabular}

Table 2: Analysis of variation between observers

\begin{tabular}{|c|c|c|c|c|c|c|c|c|c|c|c|}
\hline Observers & WSSI & $M B 2$ & $E M K 3$ & $E V / L$ & CB5 & DLT6 & $E M L 7$ & IHPB & $E A 9$ & & $\begin{array}{l}\text { Mean } \\
\text { All } \\
\text { servers }\end{array}$ \\
\hline Mean deviation & 0.87 & 1.23 & 1.55 & 2.01 & 0.84 & 0.54 & 0.53 & 0.94 & 1.19 & 1.48 & 1.12 \\
\hline Max deviation & 1.38 & 1.58 & 2.64 & 4.93 & 1.65 & 0.97 & 0.94 & 1.89 & 1.75 & 2.98 & 2.01 \\
\hline Sid doviation & 0.34 & 0.27 & 0.67 & 1.19 & 0.44 & 0.29 & 0.25 & 0.56 & 0.31 & 0.98 & 0.53 \\
\hline
\end{tabular}

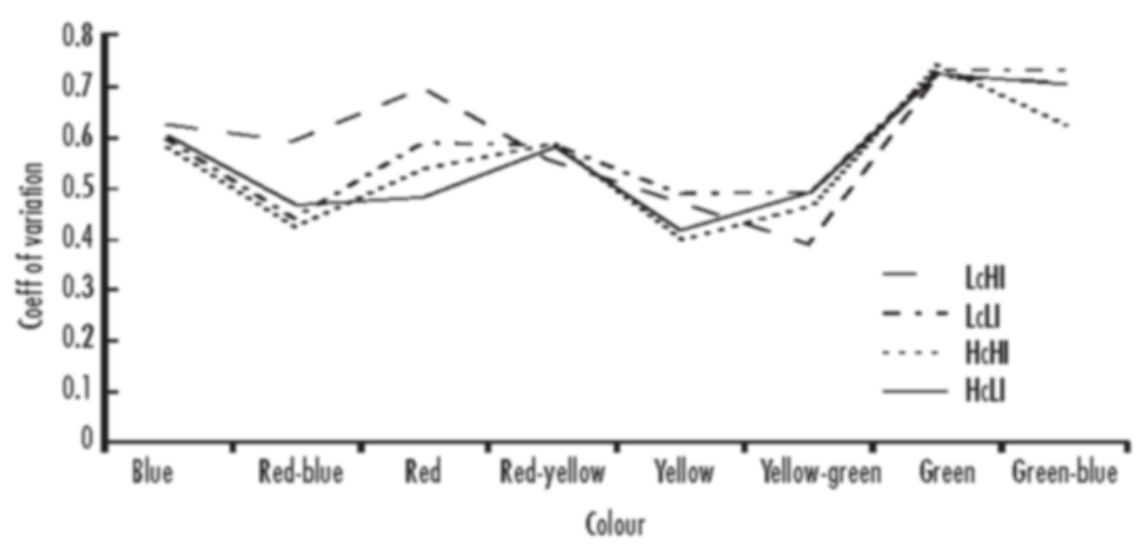

Figure 1: Coefficient of variation in $\Delta E$ across all observers for each colour set

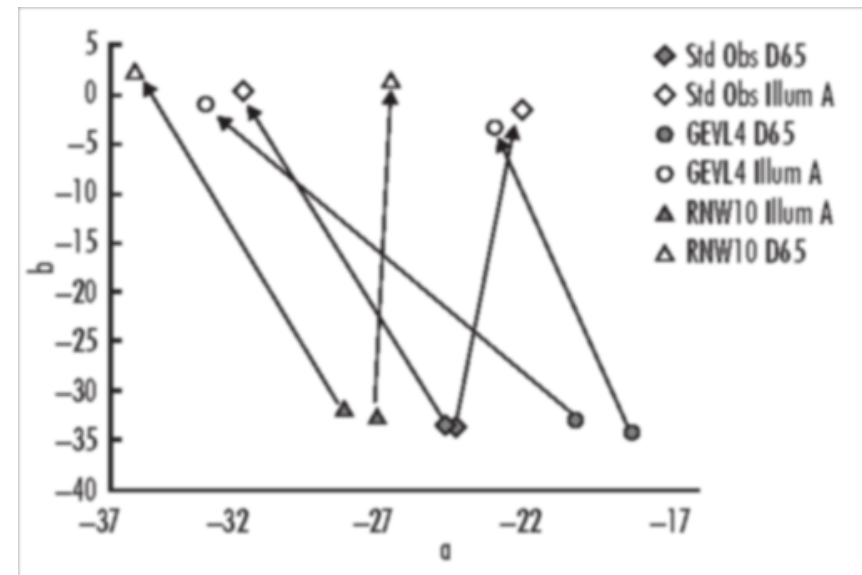

Figure 2: Combined illuminant and observer-metameric effects. All three observers see different illuminant-metameric shifts

mentary $10^{\circ}$ Observer) obtained for each of the test observers, across all the colours. The mean mismatch obtained for all the colours and all the observers is $\Delta E=1.12$. Five observers out of ten have mean $\Delta E$ across the set of colours of more than 1 . The maxima (overall maximum $\Delta E=4.33$ ) represent substantial colour identity deviations. 
Figure 1 shows what the coefficient of variation from the Standard Observer mean in each hue group. A distinct difference in variability is apparent, between the red-green differentiation channel and the yellow-blue channel. Variation between observers appears to be lower in the evolutionarily older yellow-blue differentiating mechanism.

Figure 2 shows the results for the Standard Observer and two individual Observers, when viewing a metameric pair of high-chroma low-lightness blues. One member of the pair is a measured curve cone of the previously used 32 samples) and the other member is a synthetically generated metamer of the measured curve.

Under llluminant $\mathrm{D}_{65}$, the Standard Observer sees the metameric pair of curves as a colour match (AE (CMC 2:1) $<0.2$ ), whilst actual Observer GEVL4 sees the pair as a slight mismatch with $\Delta E=1.1$.

Observer GEVL4 sees both samples as a somewhat redder blue than the Standard Observer sees them, with an $\Delta E$ between the Standard Observer identity and Actual Observer identity of more than 2.5 .

Observer RNW10 sees the pair as an acceptable match $(\mathrm{AE}=0.8)$ under $\mathrm{D}_{6.5}$ but as a somewhat greener blue than the Standard Observer. This variation demonstrates the tendency of observermetameric effects to produce perceptible colour identity disagreements between different observers. The three observers disagree about the hue of the pair.

On changing the Illuminant to Standard Illuminant A, a hue and chroma shift is produced for both the Standard and the individual Observers, resulting for all observers in a considerable colour change (up to $\triangle E=20$ ). For the Standard Observer, both of the metamers become greener, with one becoming less saturated (redder). One member of the pair is now a more saturated version and there is a difference almost entirely chro$\mathrm{ma}$, with an $\Delta \mathrm{E}$ between the two previously matching metamers of just over six units (CMC (2:1)).

Observer RNW10 sees a similar pattern of colour shift, but a slightly larger greener shift is seen, and a slightly larger metameric difference on change of illuminant is observed.

For Observer GEVL4 the pattern of illuminant metameric change is similar to that of the Standard Observer, but both the green shift, and the desaturation of one member of the pair is somewhat accentuated.

\section{Discussion}

Wyszecki and Stiles, by examination of the Stiles and Burch $10^{\circ}$ colour matching individual observer curves, conclude that the colour matching properties of individual observers ... differ from those of the ideal representative observer by more than can be ascribed to random variation in actual matching measurement. $^{\prime 2}$

Using the proposed Metamerism Index and the CMFs quoted by Wyszecki and Stiles, all of the test observers are found to be significantly observer-metameric.

If these observers (being some of the component observers of the Standard Observer) are representative of the rest of the actual observer population then the question must asked: 'why then is the Standard Observer a generally very good predictor of illuminant metameric matches?'

The answer is shown in part by Figure 2, which demonstrates that illuminantmetameric effects are similar in individual observers to those of the Standard Observer. It can also be demonstrated that by calculating the average of two or more individual CMFs the averaged response tends to have a lower Metamerism Index, indicating reduced observer-metameric properties.

This conclusion has also be supported in practice by comparing multiple-observer panel-consensus judgements of acceptability with measured colour difference. Panel-majority judgement is regarded as much more consistent than individualobserver judgement of both perceptibility and acceptability. ${ }^{4}$

Observer Metamerism is in principle a multi-dimensional phenomenon. This means that identifying all possible combinatorial instances can not be achieved unless a very large number of reflectance curve/observer test-pair comparisons are made. Representative sampling is used in this paper to give a practical approximation of the overall phenomenon. Its intent is to identify an individual's potential for observer-metameric disagreement with the Standard Observer. Both the generality of the phenomenon and its likely size are tested across the representative colour-space.

\section{Conclusions}

The colour-inconstancy results demonstrated in Tables 1 and 2, and Figure 1 suggest that the level of observer- metameric effects found is likely to be present very frequently in visual matching judgements by a high proportion of individual observers. The data suggests that, in practical situations, two individuals are likely to disagree on both the magnitude and direction of difference, and the presence or absence may also be disputed, of a visible metameric difference in many sample pair comparisons.

In this preliminary analysis, comparison is made between identified inter-observer variation and illuminant-metameric effects. The results show the presence of widespread observer-metameric effects across all parts of colour-space, when viewing colour atlas samples in daily use as visual reference standards (NCS Colour Atlas Samples, Dulux Dimensions version).

A colour difference for change in illuminant of $\Delta \mathrm{E}^{*}<2.0$ for a single metameric pair comparison is typically acceptable in commercial colour reproduction as a maximum difference on change of illuminant, from Illuminant $\mathrm{D}_{6=}$ to llluminant F11 (high efficiency fluorescent shop lighting), or lluminant A (domestic tungsten filament).

The authors shown that the metamerism index for change in observer described above, could be expected to have an average value of $M_{t}\left(=\Delta E^{*}\right)=1.15$ across all 320 comparisons tested. The average is for all 32 of the investigated representative colours, across ten tested Standard Observer/Individual Observer pairs. It is not limited to isolated 'awkward' colorant combinations. The colour-inconstancy revealed, is not comfortably confined to certain colours; it is present throughout a major section of colour-space and for a high proportion of the ten observers tested.

Change of Observer produces a 'colour difference' several times the size of the commercially acceptable $\Delta E^{*}$ for Change in Illuminant for several of the tested observers. The potential for disagreement is thus widespread and general.

Observer Metamerism will form a hidden underlying component to which more obvious illuminant metameric effects may well be added, potentially exceeding visual tolerance. Alternatively, there will be instances where the combined effects cancel out in an individual observer.

By comparison with single observer calculations, the Standard Observer predicts the consensus opinion of a panel of 20 observers. The prediction is the $n$ - 
dimensional average of the individually variable observer-metameric components.

Given the above level of calculated effects, it is not at all surprising that those depending on visual match acceptance may dispute a given match, which has been accepted as numerically satisfactory.

There are thus commercially important conclusions to our work: Where enduser satisfaction or good technical control of colour are concerned, it is advisable to depend on either numerical estimation of metameric shade change based on Standard Observer colour coordinates, or the consensus judgement of three or more individuals, not on the visual judgement of a single observer.

In adopting a Metamerism Index, based on three-dimensional colour difference, it is necessary to acknowledge that metamerism is a spectrally n-dimensional phenomenon, and much information is lost by reducing it to a simple scale such as $\Delta E^{*}$. The proposed index seeks to minimise this problem by representative sampling of spectral diversity.

\section{References}

1. Styles W S and I M Burch, "NPL Colour Matching Investigation: Final Report, Optica Acta, 6, 1-26, 1959

2. Wyszecki G and W S Stiles, Colour Science: Concepts and Methods, Quantitative Data and Formulae, Appendix of Extended Tables and Illustrations, Table 1, (5.5.6), Second Edition, 817-21, 1982

3. CIE Publication No 80, Metamerism Index: Change of Observer'.

4. Oulton D P, 'Computer simulation of human colour-matching pass/fail judgements', MSc Dissertation, UMIST 1982.

5. Wyszecki $G$ and W S Stiles, Colour Science: Concepts and Methods, Quantitative Data and Formulae, 169-173, 2nd edition, John Wiley \& Sons, 1982 